\title{
MANICORAL (Multimedia and network in cooperative research and learning).
}

\author{
Werner Fürst*, Roger Haagmans**, Marc Naeije**, Janni Nielsen*** \\ *Technical University of Graz, **Delft University of Technology, \\ ***Copenhagen Business School \\ ***janni.nielsen@cbs.dk
}

KEY WORDS: Distributed geoscientific research community, communication, cognition, multimedia.

The fast development of new IT-tools and communication technologies provides new opportunities for computer mediated collaboration in geographically distributed groups. One of the fields suitable for application of these technologies is collaboration among scientists. This opportunity is especially important to many of the smaller European countries where it may be difficult to maintain competent scientific research within highly specialized fields. The new tele-communication technologies provide scientists in smaller countries with opportunities to maintain close collaboration with colleagues in foreign countries in spite of dispersion in time and geographical location, and combined with multimedia to enhance visual representations of scientific data they open up radically new dimensions in research.

The MANICORAL video introduces the MANICORAL project that aims at exploring, developing, implementing and evaluating a Computer Supported Cooperative Work System among a geographically distributed European research Group. This inte- grated system optimally combines various media and high speed networking. Consequently, it will enhance international collaboration, access to scientific methods, results and data. Hence, the MANICORAL life board may become a standard tool in everyone's local scientific environment, as it will support and improve everydays scientific work regardless of location.

Especially, the video shows how Distributed Cooperative Visualization (DCV) tools can facilitate collaboration within a distributed group of scientists. The distributed group has both teaching and research obligations and the DCV tools may facilitate both. However, of these two obligations support for research is the most obvious, as here the video clearly demonstrates how the DCV tools enables the scientists to share data, interpretations and ideas over the network, and thereby, enables them to become more productive.

MANICORAL belongs to the telematics program of the European Union and unites human factors expertise, technology providers and geoscientists. 